\title{
The relationship between meaning in life and resilience in older adults: a cross-sectional study
}

\section{BACKGROUND}

Meaning in life has been considered necessary for the psychological well-being of older adults. The aim of this study was to investigate the relationship between meaning in life and resilience in the elderly in Kerman, Iran.

\section{PARTICIPANTS AND PROCEDURE}

In this cross-sectional study, 300 older adults (aged more than 60 years) were included using the multistage sampling method in Kerman in 2018. The Connor-Davidson Resilience Scale (CD-RISC) was used to investigate the resilience status, and for assessing meaning of life, Steger's meaning in life questionnaire was employed. Data were analyzed using Pearson correlation, chi-square, $t$-test, ANOVA and linear regression by IBM SPSS V21.

\section{RESULTS}

The mean age of participants was $67.3 \pm 7.9$ years. Resilience status was significantly different in terms of gender $(p=.021)$, educational status $(p=.032)$, and self-reported health status $(p=.003)$. There was a significant positive relationship between meaning in life and resilience $(r=.38$, $p=.012$ ). Independent variables (meaning in life, self-reported health status, gender) accounted for $31 \%$ of the variance in resilience $(p \leq .001)$.

\section{CONCLUSIONS}

Considering meaning in life and resilience in older adults helps to improve psychological health and wellness and create a unique potential ability to confront the pitfalls of old age, which result in better physical, mental, social, and spiritual health in older adults.

\section{KEY WORDS}

meaning in life; resilience; older adults; self-reported health status

ORGANIZATION - 1: Social Determinants of Health Research Center, Institute for Futures Studies in Health, Kerman University of Medical Sciences, Kerman, Iran · 2: HIV/STI Surveillance Research Center, and WHO Collaborating Center for HIV Surveillance, Institute for Futures Studies in Health, Kerman University of Medical Sciences, Kerman, Iran .

3: Physiology Research Center, Institute of Neuropharmacology, Kerman University of Medical Sciences, Kerman, Iran .

4: Department of Aging, University of Social Welfare and Rehabilitation Sciences, Tehran, Iran · 5: Neuroscience

Research Center, Institute of Neuropharmacology, Kerman University of Medical Sciences, Kerman, Iran aUthors' Contributions - A: Study design - B: Data collection - C: Statistical analysis · D: Data interpretation .

E: Manuscript preparation · F: Literature search · G: Funds collection

CORRESPONDING AUthor - Vahidreza Borhaninejad, Ph.D., Neuroscience Research Center, Institute of Neuropharmacology,

Kerman University of Medical Sciences, Haft-Bagh Highway, 76169-13555 Kerman, Iran, e-mail: borhani777@yahoo.com to Cite this ARTICle - Mohseni, M., Iranpour, A., Naghibzadeh-Tahami, A., Kazazi, L., \& Borhaninejad, V. (2019).

The relationship between meaning in life and resilience in older adults: a cross-sectional study. Health Psychology

Report, 7(2), 133-138. https://doi.org/10.5114/hpr.2019.85659

RECEIVED 20.04.2019 • REVIEWED 06.05.2019 • ACCEPTED 14.05.2019 • PUBLISHED 04.06.2019 


\section{BACKGROUND}

Ageing, as a physiological process, is an inevitable process and has increased incidence of chronic diseases in human (Parnicka, 2018). So the majority of older adults seek to use healthcare services across the world (Borhaninejad, Naghibzadeh-Tahami, Nabavi, Rashedi, \& Yazdi-Feyzabadi, 2015). Almost 70\% of the elderly have several chronic diseases and are at higher risk of disability and death (Woo et al., 2007).

Mohabbat

Mohseni,

Abedin Iranpour, Ahmad

Naghibzadeh-

Tahami,

Leila Kazazi,

Vahidreza

Borhaninejad
These diseases, along with mental and psychological problems including anxiety and depression, can increase the burden of family caregiving and financial difficulties (Borhaninejad et al., 2014; Ebrahimi, Hosseini, \& Rashedi, 2018). Thus, researchers are seeking health approaches in the three aspects of getting rid of disease, being active in life, and developing physical and mental skills to respond to some of these demands (Addae-Dapaah \& Juan, 2014).

In the area of mental skills development, positivistic psychological approaches such as the existence of meaning in life have been considered necessary for the psychological well-being of individuals, especially in middle-age and later life (King, Hicks, Krull, $\&$ Del Gaiso, 2006). There is no unique definition for the meaning in life, but it is often defined as a person's feeling of having a goal in life or spending time and energy to achieve valuable goals (Bhattacharya, 2011). It is considered as a positive variable and indicator of psychological well-being (de Muijnck, 2013), that is not only the main source of motivation for human activities (Henry et al., 2014), but also is a preventable indicator for violence and suicide (Debats, Van der Lubbe, \& Wezeman, 1993). Based upon the previous studies, lack of meaning in life is associated with the need for psychological treatments, depression, anxiety, suicidal ideation, and drug abuse (Harlow, Newcomb, \& Bentler, 1987; Mesrabadi, Jafariyan, \& Ostovar, 2013). Meaning in life would help individuals to improve their psychological adaptation and resistance against psychological problems and mental disorders (Mesrabadi et al., 2013). As reported by Du et al., having a goal in life would improve health status (Ungar, 2011).

Due to the prevalence of psychophysical problems, especially chronic diseases, the importance of a dynamic and complex process to confront these problems is apparent, which is called the resilience process (Windle, 2011). Some consider resilience as an intrinsic characteristic of humans to moderate stress and adapt to different conditions (Waller, 2001). Resilience is an important factor in adapting successfully to changes, and enhancing the ability to resist problems that make it possible for individuals to benefit from their adaptive skills and turn stressful situations into an opportunity to learn and grow, and focus on the problem to control their stress (Connor \& Davidson, 2003; Orang, Hashemi Razini, \& Ramshini, 2018).
According to the results of a study by Jeste et al., resilience is considered as a positive factor in achieving functional independence and successful aging (Jeste et al., 2013). Another study showed that meaning in life is associated with lower levels of depression and loneliness in people with a high level of resilience. Also, some of the characteristics of resilient people, such as purposefulness and belief in a clear future, optimism, religious beliefs, and spiritual relationships, have the same relationship with meaning in life (Masten, 2001).

Elderly people need to re-evaluate their goals to achieve the excellence needed for the aging period. On the other hand, it seems that the existence of positive or negative schemas from pre-elderly age is related to coping with aging. Considering the positive role of having a goal and meaning in life as well as resilience in order to cope with the problems and dysfunctions in the elderly, the present study was conducted to investigate the relationship between meaning in life and resiliency in the elderly.

\section{PARTICIPANTS AND PROCEDURE}

This is a descriptive cross-sectional study. In this study, 300 older people (over 60 years old) were included in the study using multi-stage cluster sampling in Kerman. For this purpose, 75 elderly people were randomly selected considering the household number from 4 centers of 10 health centers in different regions in Kerman. Before interviews, informed consent was obtained from older adults. Then, the researcher referred to the elderly person's address and filled in the questionnaire through face-to-face interviews. The participants were those who were willing to participate in the study and had adequate and appropriate literacy. This research was approved by the Ethics Committee of Kerman University of Medical Sciences (Code No: IR.KMU.REC.1397.026).

In order to determine the sample size, considering a $95 \%$ confidence $(\alpha=.05, Z=1.96)$ as well as an accuracy of $7 \%$ and assuming that $50 \%$ of the participants have favorable resilience the sample size of 200 was obtained. Considering the design effect, the sample size was calculated as 300 persons.

The inclusion criteria were: age equal to or above 60 years, complete patient record file, diagnosed citizen of Iran, and ready to provide informed consent to use data and participate. Those not meeting these requirements were not included in our survey. Data were collected using a demographic questionnaire and self-reported health status of the elderly (including very good, good, not good, not bad, bad, and very bad). The first questionnaire was the Connor-Davidson Resilience Scale (CD-RISC) containing 25 (5-point) Likert scale questions $(0$ - not true at all, 1 - rarely true, 2 - sometimes true, 3 - often true, 
4 - true nearly all of the time) that measured the ability to cope with pressure and threats. The test scores ranged from 0 to 100 , and higher scores represented higher levels of resilience in the subjects. The validity of this scale has been standardized in Iranref. To determine the reliability of the scale, Cronbach's $\alpha$ method was used and the reliability coefficient was found to be .89 . Steger's meaning in life questionnaire that includes 10 (7-point) Likert scale questions from 1 (absolutely true) to 7 (absolutely untrue) was used to measure the meaning in life. The validity of the questionnaire was confirmed by the experts' opinions with Cronbach's $\alpha$ of .85 (Steger, Mann, Michels, \& Cooper, 2009).

Data were analyzed using SPSS version 21 . The normality of the data was confirmed using the Kolmogorov-Smirnov test.

\section{RESULTS}

In this study, 282 out of 300 questionnaires were filled in completely and analyzed. The mean age of the older people was $67.3 \pm 7.9$ years. Among the participants, $56.4 \%$ were female. The majority of the participants were married (71.2\%), 63.4\% had lower than high school education, $51.4 \%$ reported a moderate health status, and about one-fourth (24.5\%) reported a good health status.

Table 1 shows the mean scores of participants' resilience based on the demographic characteristics of the participants. As shown in this table, there was a significant difference in the scores of participants' resilience in terms of gender and educational status. Also, there was a significant difference in the scores of participants' resilience in terms of the health status, so that the elderly who reported a good health status showed a higher level of resilience (Table 1).

Also, the results of Pearson's correlation test showed that there was a significant relationship between meaning in life and resilience (Table 2).

To determine the relationship of meaning in life and independent variables with resilience, linear regression was used. Regarding the final model of regression analysis, meaning in life, health status, educational status and gender were considered as determinants of resilience. In total, $0.31 \%$ of the variance of resilience is explained by these determinants $(p \leq .001)$ (Table 3).

\section{DISCUSSION}

The aim of this study was to investigate the relationship between meaning in life and resilience, and also to determine the ability of the variables of gender, marital status, educational status, and health status
Table 1

Description of group difference between mean resilience and socio-demographic measures

\begin{tabular}{|c|c|c|c|c|}
\hline Variables & $M$ & $S D$ & Score & $p$ \\
\hline \multicolumn{5}{|l|}{ Marital status } \\
\hline Single & 67.33 & 20.01 & $1.45^{\mathrm{t}}$ & .252 \\
\hline Married & 65.01 & 25.44 & & \\
\hline \multicolumn{5}{|l|}{ Gender } \\
\hline Male & 68.08 & 18.23 & $-2.32^{\mathrm{t}}$ & .021 \\
\hline Female & 62.26 & 15.27 & & \\
\hline \multicolumn{5}{|l|}{ Education } \\
\hline Illiterate & 56.22 & 24.11 & $2.88^{\mathrm{F}}$ & .032 \\
\hline Primary & 63.24 & 14.01 & & \\
\hline $\begin{array}{l}\text { Under } \\
\text { diploma }\end{array}$ & 71.85 & 19.63 & & \\
\hline Diploma & 66.28 & 15.14 & & \\
\hline Academic & 64.48 & 17.44 & & \\
\hline \multicolumn{5}{|l|}{$\mathrm{SRH}$} \\
\hline Very good & 72.45 & 15.20 & $4.01^{\mathrm{F}}$ & .003 \\
\hline Good & 64.10 & 16.21 & & \\
\hline $\begin{array}{l}\text { Not good, } \\
\text { not bad }\end{array}$ & 60.12 & 16.58 & & \\
\hline Bad & 62.47 & 18.25 & & \\
\hline Very bad & 44.85 & 24.96 & & \\
\hline
\end{tabular}

Note. $\mathrm{t}$ - Independent-samples t-test, F - One-way ANOVA.

Table 2

Correlation analysis of meaning in life and resilience

\begin{tabular}{lcc}
\hline Variable & $\begin{array}{c}\text { Meaning } \\
\text { in life }\end{array}$ & Resilience \\
\hline Meaning in life & 1.00 & 0.38 \\
Resilience & 0.38 & 1.00 \\
\hline
\end{tabular}

Note. ${ }^{*}$ significance level .01.

Table 3

Regression analysis of meaning in life in predicting resilience in the studied subjects

\begin{tabular}{lcccc}
\hline $\begin{array}{l}\text { Independent } \\
\text { variables }\end{array}$ & $R^{2}$ & $\beta$ & $t$ & $p$ \\
\hline Gender & .31 & .16 & 2.47 & .011 \\
Education & & .40 & 0.90 & .030 \\
SRH & .19 & -2.90 & .004 \\
$\begin{array}{l}\text { Meaning } \\
\text { in life }\end{array}$ & .35 & 5.44 & $<.001$ \\
\hline
\end{tabular}

Relationship between meaning in life and resilience in older adults 
to predict resilience in the elderly. The findings indicated that gender, educational status, health status, and meaning in life have a significant relationship with resilience in the elderly; therefore, these factors can potentially predict and explain some of the changes in resilience.

The mean level of resilience in this study was consistent with the results of another study in Iran (IzadiAvanji, Kondabi, Reza Afazel, Akbari, \& ZeraatiNasrabady, 2017). In contrast, Phillips et al. reported a similar level of resilience in elderly men and women (Phillips, Auais, Belanger, Alvarado, \& Zunzunegui, 2016). In another study in England, the level of resilience in elderly women was higher than that in elderly men (Netuveli, Wiggins, Montgomery, Hildon, \& Blane, 2008). One possible explanation may relate to positive feelings, stronger support networks and social relationships, and more intimate relationships that make men socially more resilient compared to elderly women. People with higher education also reported higher levels of resilience. In a similar study in Iran, a significant relationship was observed between educational status and resilience (Izadi-Avanji et al., 2017). This consistency may be due to higher education and enough knowledge about aging problems which can facilitate the process of self-care and selfreliance, the power of judgment and decision making to adapt appropriate behaviors, and the coping strategies could increase the level of resilience. Also, people who reported better health status had higher levels of resilience. Similar studies also showed that elderly people who suffer from chronic diseases had lower levels of resilience (Adams, Sanders, \& Auth, 2004; Felten, 2000).

The most important finding of this study was the significant relationship between meaning in life and resilience. In the study of Du et al., meaning in life had a significant relationship with lower levels of depression and loneliness and higher levels of resilience (Du, Li, Chi, Zhao, \& Zhao, 2017). Another study reported a significant relationship between meaning in life and resilience (Nygren et al., 2005). The study of Kim et al. showed that there was a significant relationship between meaning in life and resilience (Kim, Lee, Yu, Lee, \& Puig, 2005). Some studies have confirmed that lack of meaning in life can be related to some variables such as the need for psychological treatments, depression, anxiety, suicidal ideation, and drug abuse (Mesrabadi et al., 2013). It has been revealed that people who have meaning in their lives show less negative emotions towards problems, indicating relatively high levels of resilience in these people (Steger, Kashdan, Sullivan, \& Lorentz, 2008).

Findings show that high resilience can be a protective factor (Izydorczyk, Rąba, \& Sitnik-Warchulska, 2018). These findings can be interpreted to indicate that the actual abilities of human beings will only flourish with full potential if they understand the meaning of life. A person's perception of his position and place in the world and trying to find meaning in life are ways to cope with stress and adapt to life challenges. Frankl is one of the best theorists who emphasize the relationship between meaning in life and resilience. He proposed his theory in Nazi camps to help the camp prisoners escape from absurdity and find meaning in life. Accordingly, he and other prisoners could regain their mental health and find meaning in life as a preventive factor for destructive thoughts such as suicide. He believed that people who are frustrated, depressed, and restless, and those who feel loneliness and have a low level of resilience, complain about lack of meaning in life and absurdism (Frankl, 2005).

The findings of this study can be described based on Erikson's theory of psychosocial development. Accordingly, individuals at the end of life evaluate their successes and failures and look for meaning in their life. One of the major task at this stage is to give meaning to life and achieve excellence. If the elderly can find meaning in their lives, they will achieve excellence and have a positive view of their past. But if the elderly person's view of life is negative, they may lose hope and meaning in life, resulting in a reduced level of resilience and difficulty in coping with aging.

The importance of resilience to improving selfconfidence and interaction with others leads to considering the significant positive effect of meaning in life on resilience in the elderly, and paying attention to factors making life meaningful is of great importance, because today, using the concept of meaning in life in the field of counseling and psychotherapy has been increasingly taken into consideration. Meanwhile, religion by making the belief in immortality and creating religious obligations has been determined as one of the sources making life meaningful (Van Tongeren, Hook, \& Davis, 2013). Stavrova and Luhmann determined social connections and social links as the main sources making life meaningful (Stavrova \& Luhmann, 2016). Wolf considered that to be loved, accepted, and trusted by the most important persons in life are the most important factors making life meaningful (Wolf, 2016).

Some researchers also consider love as one of the sources of meaning in life (Henry et al., 2014). As can be seen, definition and finding about meaning in life and its effects on life are very different, which may be due to the complexity of the concept of meaning in life that results in different conceptions of the relationship between meaning in life and other variables such as resilience. Since the conditions and complexity of mechanical life of the human being require the adaptation of coping strategies, accordingly, today, positivistic psychological approaches, and consequently, the concept of resilience has attracted the attention of psychologists and counselors in recent years. Therefore, it is recommended to pay more at- 
tention to the concepts related to the meaning in life that have a positive relationship with resilience in individuals.

Also, some studies have reported that trying to find a meaning in life can lead to negative emotions and reduce happiness in people, because people who search for meaning in their lives may experience high levels of stress by causing contradiction between the reality of life and what people hope to achieve, and creates ambiguity in people's lives (Park, Park, \& Peterson, 2010).

\section{CONCLUSIONS}

According to the findings, there is a relationship between meaning in life and resilience in the participants of this study. In other words, older people with higher levels of resilience have more favorable physical, mental, social, and spiritual health. Therefore, it is recommended to consider this factor in planning for educational interventions and counseling for elder people.

\section{LIMITATIONS}

The limitations of this study include the use of self-report questionnaires; and the researchers did not take into account the role of other variables such as personality traits and daily life stress of the participants.

\section{IMPLICATIONS}

The findings of this study may be useful for families, professors, counselors, planners, policy makers, and all those who are in some way associated with such participants.

\section{REFERENCES}

Adams, K. B., Sanders, S., \& Auth, E. (2004). Loneliness and depression in independent living retirement communities: risk and resilience factors. Aging \& Mental Health, 8, 475-485.

Addae-Dapaah, K., \& Juan, Q. S. (2014). Life satisfaction among elderly households in public rental housing in Singapore. Health, 6, 1057-1076.

Bhattacharya, A. (2011). Meaning in life: A qualitative inquiry into the life of young adults. Psychological Studies, 56, 280-288.

Borhaninejad, V., Momenabadi, V., Hosseini, S., Mansori, T., Sadeghi, A., \& Toroski, M. (2014). Health physical and mental status in the elderly of Kerman. Journal of North Khorasan University of Medical Sciences, 6, 715-725.
Borhaninejad, V., Naghibzadeh-Tahami, A., Nabavi, H., Rashedi, V., \& Yazdi-Feyzabadi, V. (2015). The utilization of health services and its influences among elderly people in Kerman-2014. Journal of North Khorasan University of Medical Sciences, 7, 229-240.

Connor, K. M., \& Davidson, J. R. (2003). Development of a new resilience scale: The Connor-Davidson resilience scale (CD-RISC). Depression and Anxiety, 18, 76-82.

de Muijnck, W. (2013). The meaning of lives and the meaning of things. Journal of Happiness Studies, 14, 1291-1307.

Debats, D. L., Van der Lubbe, P. M., \& Wezeman, F. R. (1993). On the psychometric properties of the Life Regard Index (LRI): A measure of meaningful life: An evaluation in three independent samples based on the Dutch version. Personality and Individual Differences, 14, 337-345.

Du, H., Li, X., Chi, P., Zhao, J., \& Zhao, G. (2017). Meaning in life, resilience, and psychological wellbeing among children affected by parental HIV. AIDS Care, 29, 1410-1416.

Ebrahimi, B., Hosseini, M., \& Rashedi, V. (2018). The Relationship between social support and death anxiety among the elderly. Elderly Health Journal, 4, 37-42.

Felten, B. S. (2000). Resilience in a multicultural sample of community-dwelling women older than age 85. Clinical Nursing Research, 9, 102-123.

Frankl, V. (2005). Founder of logotherapy overview on psychology and existential psychotherapy. Tehran: Danjheh.

Harlow, L. L., Newcomb, M. D., \& Bentler, P. (1987). Purpose in life test assessment using latent variable methods. British Journal of Clinical Psychology, 26, 235-236.

Henry, K. L., Lovegrove, P. J., Steger, M. F., Chen, P. Y., Cigularov, K. P., \& Tomazic, R. G. (2014). The potential role of meaning in life in the relationship between bullying victimization and suicidal ideation. Journal of Youth and Adolescence, 43, 221-232.

Izadi-Avanji, F. S., Kondabi, F., Reza Afazel, M., Akbari, H., \& Zeraati-Nasrabady, M. (2017). Measurement and predictors of resilience among community-dwelling elderly in Kashan, Iran: A cross-sectional study. Nursing and Midwifery Studies, 6, e36397.

Izydorczyk, B., Rąba, M., \& Sitnik-Warchulska, K. (2018). Resilience, self-esteem, and body attitude in women from early to late adulthood. Health Psychology Report, 6, 193-206.

Jeste, D. V., Savla, G. N., Thompson, W. K., Vahia, I. V., Glorioso, D. K., Martin, A. S., Palmer, B. W., Rock, D., Golshan, S., Kraemer, H. C., \& Depp, C. A. (2013). Association between older age and more successful aging: critical role of resilience and depression. American Journal of Psychiatry, 170, 188-196.

Kim, T. H., Lee, S. M., Yu, K., Lee, S., \& Puig, A. (2005). Hope and the meaning of life as influences on Ko-
Relationship between meaning in life and resilience in older adults 
rean adolescents' resilience: Implications for counselors. Asia Pacific Education Review, 6, 143-152.

King, L. A., Hicks, J. A., Krull, J. L., \& Del Gaiso, A. K. (2006). Positive affect and the experience of meaning in life. Journal of Personality and Social Psychology, 90, 179-196.

Masten, A. S. (2001). Ordinary magic: Resilience processes in development. American Psychologist, 56, 227-238.

Mesrabadi, J., Jafariyan, S., \& Ostovar, N. (2013). Dis-

Mohabbat

Mohseni,

Abedin Iranpour,

Ahmad

Naghibzadeh-

Tahami,

Leila Kazazi,

Vahidreza

Borhaninejad

criminative and construct validity of meaning in life questionnaire for Iranian students. International Journal of Behavioral Sciences, 7, 83-90.

Netuveli, G., Wiggins, R. D., Montgomery, S. M., Hildon, Z., \& Blane, D. (2008). Mental health and resilience at older ages: Bouncing back after adversity in the British Household Panel Survey. Journal of Epidemiology \& Community Health, 62, 987-991.
Nygren, B., Aléx, L., Jonsén, E., Gustafson, Y., Norberg, A., \& Lundman, B. (2005). Resilience, sense of coherence, purpose in life and self-transcendence in relation to perceived physical and mental health among the oldest old. Aging \& Mental Health, 9, 354-362.

Orang, S., Hashemi Razini, H., \& Ramshini, M. (2018). Investigating the meaning of life and psychological well-being in youth, adults, and elderly (a comparative study of three age groups). Iranian Journal of Ageing, 13, 182-197.

Park, N., Park, M., \& Peterson, C. (2010). When is the search for meaning related to life satisfaction? Applied Psychology: Health and Well-Being, 2, 1-13.

Parnicka, U. (2018). Physical activity in promoting health of the elderly. Health Problems of Civilization, 12, 265-271.

Phillips, S. P., Auais, M., Belanger, E., Alvarado, B., \& Zunzunegui, M. V. (2016). Life-course social and economic circumstances, gender, and resilience in older adults: The longitudinal International Mobility in Aging Study (IMIAS). SSM-Population Health, 2, 708-717.

Stavrova, O., \& Luhmann, M. (2016). Social connectedness as a source and consequence of meaning in life. The Journal of Positive Psychology, 11, 470-479.

Steger, M. F., Kashdan, T. B., Sullivan, B. A., \& Lorentz, D. (2008). Understanding the search for meaning in life: Personality, cognitive style, and the dynamic between seeking and experiencing meaning. Journal of Personality, 76, 199-228.

Steger, M. F., Mann, J. R., Michels, P., \& Cooper, T. C. (2009). Meaning in life, anxiety, depression, and general health among smoking cessation patients. Journal of Psychosomatic Research, 67, 353-358.

Ungar, M. (2011). The social ecology of resilience: Addressing contextual and cultural ambiguity of a nascent construct. American Journal of Orthopsychiatry, 81, 1-17.
Van Tongeren, D. R., Hook, J. N., \& Davis, D. E. (2013). Defensive religion as a source of meaning in life: A dual mediational model. Psychology of Religion and Spirituality, 5, 227-232.

Waller, M. A. (2001). Resilience in ecosystemic context: Evolution of the concept. American Journal of Orthopsychiatry, 71, 290-297.

Windle, G. (2011). What is resilience? A review and concept analysis. Reviews in Clinical Gerontology, 21, 152-169.

Wolf, S. (2016). Meaning in life: Meeting the challenges. Foundations of Science, 21, 279-282.

Woo, E. K., Han, C., Jo, S. A., Park, M. K., Kim, S., Kim, E., Park, M. H., Lee, J., \& Jo, I. (2007). Morbidity and related factors among elderly people in South Korea: results from the Ansan Geriatric (AGE) cohort study. BMC Public Health, 7, 10. 